\title{
PYODERMA GANGRENOSUM ASSOCIATED WITH RHEUMATOID ARTHRITIS: A CASE REPORT
}

Marina Coelho Moraes de Brito ${ }^{1, *}$, Kaliana Maria Nascimento Dias de Almeida², André Bezerra Sena ${ }^{1}$, Luca Terracini Dompieri, Mário Petrônio Dowsley de Freitas Neto², Raphael Oitaven Andrade Amorim ${ }^{1}$, Iolanda Galbiati Rodrigues de Oliveira², Emílio Melo², Fernando Gondim², Andrea Tavares Dantas ${ }^{1,2}$

1.Universidade Federal de Pernambuco, Recife (PE), Brazil. 2.Hospital Metropolitano Norte Miguel Arraes de Alencar, Paulista (PE), Brazil.

*Corresponding author: marina.cmbrito@gmail.com

\section{BACKGROUND}

Pyoderma gangrenosum (PG) is an inflammatory neutrophilic dermatosis. It starts as a papule or pustule that enlarges and erodes into a necrotic and painful ulcer. It can occur in any skin surface, most frequently reported in the lower extremities. It is a rare condition, associated with underlying comorbidities in more than $50 \%$ of the cases, being the main association reported with inflammatory bowel disease (IBD). Only a few epidemiological studies were performed, and the percentage of PG associated with rheumatoid arthritis (RA) remains unclear. In a cohort study by Ashchyan et al., among 356 patients diagnosed with PG, RA was found in $8.4 \%(n=30)$. This is a case report of a patient with RA presenting with PG in her lower left limb.

\section{CASE REPORT}

A 53-year-old woman with a previous diagnosis of RA, who abandoned treatment with methotrexate and prednisone a year before admission, presented with an endured lesion in her left lower extremity, which evolved in a few days into a painful ulcerative lesion. The patient took cephalexin and silver sulfadiazine by herself, and, without improvement, reached for an emergency care unit where levofloxacin was prescribed considering a cutaneous infection. Within two weeks, the lesion expanded to an extensive ulcer in almost 70\% of the lower extremity, friable and with active bleeding (Fig. 1). The patient had a previous hospital admission in 2014 with a similar condition, a lesion on her tight of approximately $30 \mathrm{~cm}$ of diameter and biopsy confirmation of PG. Colonoscopy with biopsy was performed and ruled out IBD, defining RA as her underlying condition. The patient was hospitalized, and prednisone $60 \mathrm{mg} /$ day was prescribed, associated with ceftriaxone and clindamycin, once there were signs of secondary infection. The lesion did not respond to the treatment instituted, being prescribed azathioprine $100 \mathrm{mg} /$ day. The patient had marked improvement of the pain and in the aspect of the lesion, that associated with the previous histopathological diagnosis, endorses the PG confirmation. She was discharged 10 days after the admission, using corticosteroid and azathioprine.

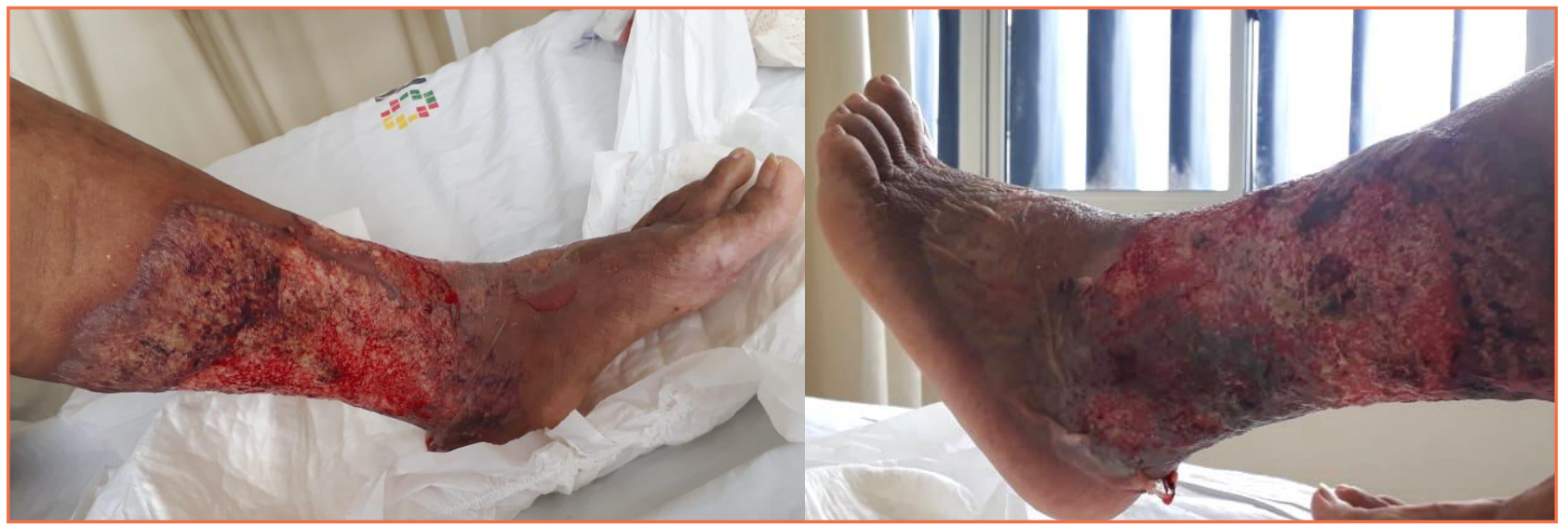

Figure 1. Aspect of the patient's lesion.

\section{CONCLUSION}

We report a case of $\mathrm{PG}$, initially misdiagnosed, delaying the appropriate treatment. It is an inflammatory condition more commonly related with IBD, infrequent in rheumatological diseases. This case emphasizes the importance of its association with RA, mainly because of the relevance of PG in morbidity, aiming to change the prognosis of these patients instituting precocious treatment. 